\title{
Wise surgeons learn from others' experiences
}

\author{
Toyofumi F. Chen-Yoshikawa, MD
}

\author{
From the Department of Thoracic Surgery, Kyoto University Graduate School of Medicine, Kyoto, Japan. \\ Disclosures: Author has nothing to disclose with regard to commercial support. \\ Received for publication Nov 14, 2017; accepted for publication Nov 16, 2017; available ahead of print Dec 9, \\ 2017. \\ Address for reprints: Toyofumi F. Chen-Yoshikawa, MD, Department of Thoracic Surgery, Kyoto University \\ Graduate School of Medicine, 54 Shogoin Kawahara-cho, Sakyo-ku, Kyoto 606-8507, Japan (E-mail: \\ tfchenyoshikawa@gmail.com). \\ J Thorac Cardiovasc Surg 2018;155:e115 \\ $0022-5223 / \$ 36.00$ \\ Copyright (C) 2017 by The American Association for Thoracic Surgery \\ https://doi.org/10.1016/j.jtcvs.2017.11.047
}

With the development and availability of thin-slice computed tomography, many thoracic surgeons now encounter a situation in which a small nodule is incidentally detected in patients without symptoms. Video-assisted thoracoscopic surgery (VATS) is performed for such nodules. In Japan, approximately $70 \%$ of lung cancer surgeries are performed by VATS, and the number of VATS procedures that use only a monitor for visualization, often called "complete VATS," is increasing. ' Robotic segmentectomy and singleport segmentectomy are also in widespread use. In fact, VATS sublobar resection, including segmentectomy, is also a treatment option for small nodules, as in the case report in this issue of the Journal by Li and colleagues. ${ }^{2}$

In general, VATS segmentectomy is not as easy as VATS lobectomy. The most important technical process in anatomic segmentectomy is the division of the intersegmental plane. The visualization of an intersegmental plane is therefore a key process in VATS segmentectomy. Several methods are used to identify an intersegmental plane in VATS segmentectomy, and an inflation technique is performed in many institutions. In their case report, Li and colleagues $^{2}$ report an episode of intraoperative cardiac arrest caused by air embolism during VATS segmentectomy. This is a rare but potentially fatal complication. At least 2 similar cases have been reported and were cited in the case report as important references. In all 3 cases, including that of $\mathrm{Li}$ and colleagues, ${ }^{2}$ a needle was used to inject air into the targeted segmental bronchus. These 3 patients survived and recovered, although 1 patient had hemiplegia develop. More patients may have experienced this complication, however, because procedure-related deaths tend not to be reported in the literature. Although this complication has previously been reported, the case report of $\mathrm{Li}$ and colleagues ${ }^{2}$ includes a video file that will provide further warning to thoracic surgeons. More importantly, $\mathrm{Li}$ and colleagues $^{2}$ encountered a potentially fatal intraoperative

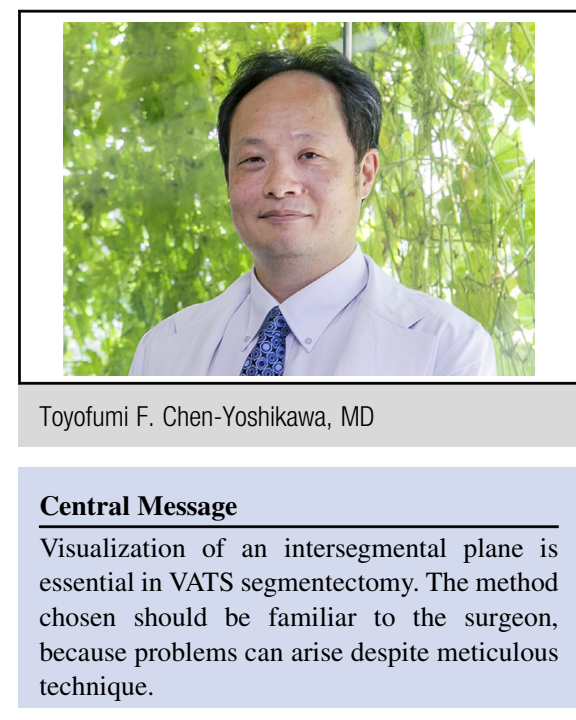

See Article page e111.

complication, but their prompt and appropriate treatment saved the patient without sequelae.

To minimize the occurrence of such fatal complications, Kamiyoshihara and associates ${ }^{3}$ described several techniques that can be used during VATS segmentectomy, which $\mathrm{Li}$ and colleagues ${ }^{2}$ also discussed in their report. Others might recommend methods that include 3-dimensional computed tomography, such as video-assisted lung mapping with a transbronchial dye injection. ${ }^{1}$

In summary, $\mathrm{Li}$ and colleagues ${ }^{2}$ encountered a potentially fatal complication, but they are to be congratulated on their prompt and appropriate treatment. No matter how careful we are, problems can occur. Although this is just a case report, wise thoracic surgeons should learn from this potentially lethal complication. It is hoped that the report of this rare complication will provide further warning to thoracic surgeons performing VATS segmentectomy.

\section{References}

1. Chen-Yoshikawa TF, Date H. Update on three-dimensional image reconstruction for preoperative simulation in thoracic surgery. J Thorac Dis. 2016;8(Suppl 3): S295-301.

2. Li NL, Lin CS, Shih CH, Liu CC. Intraoperative cardiac arrest caused by air embolism during video-assisted thoracoscopic segmentectomy. J Thorac Cardiovasc Surg. 2018;155:e111-3.

3. Kamiyoshihara M, Nagashima T, Igai H. The selected segmental inflation technique for pulmonary segmentectomy: pros and cons. J Thorac Cardiovasc Surg. 2012;143:990-1. author reply 991-2. 